\title{
A secularização no pensamento de Charles Taylor: uma análise de resultado de pesquisa
}

\section{Secularization in Charles Taylor's thought: an analysis of research results}

\section{La secularización en el pensamiento de Charles Taylor: un análisis de resultado de una investigación}

\author{
Breno Martins Campos* \\ Josner Jeudy**
}

Submetido em: 2-1-2021

Aceito em: 7-6-2021

\author{
* Pontifícia Universidade Católica de Campinas \\ (PUC-Campinas) \\ E-mail: brenomartinscampos@gmail.com> \\ ** Pontifícia Universidade Católica de Campinas \\ (PUC-Campinas). \\ E-mail: shalomadonai883@yahoo.fr
}

\begin{abstract}
RESUMO
Segundo os dados quantitativos aferidos por Maurílio Ribeiro da Silva, em sua religiografia das pesquisas sobre a temática da secularização nos Programas de Pós-Graduação em Ciências da Religião no Brasil, podemos observar que o assunto (secularização) interessa cada vez mais aos estudos de religião no Brasil; além disso, notamos que o autor Charles Taylor - mesmo com toda a importância de sua obra-prima, o livro Uma era secular - pode ser considerado ainda pouco debatido em teses e dissertações defendidas na área das Ciências da Religião em nosso país. Assim, trata-se este texto, original em sua concepção e redação, e fundamentado em perspectiva metodológica bibliográfica e exploratória, de uma "análise de resultado de pesquisa" (categoria específica de trabalho científico) sobre a dissertação - inserida num cenário temático ampliado acerca da secularização, seus sentidos e suas consequências no mundo moderno ocidental.

Palavras-chave: Modernidade; secularização; fé; Charles Taylor; Ciências da Religião.
\end{abstract}

\begin{abstract}
According to the quantitative data obtained by Maurílio Ribeiro da Silva, in his religiography (state of the art) of research on the theme of secularization in the Graduate Programs in Sciences of Religion in Brazil, we can observe that the subject (secularization) is of increasing interest to religious Studies in Brazil. Furthermore, we note that the author Charles Taylor - even with all the importance of his masterpiece, A Secular Age - is still not frequently discussed in theses and dissertations defended in the area of Religious Sciences in Brazil. Thus, this text, original in its conception and writing, and based on a bibliographic and exploratory methodological perspective, is a "research result analysis" (specific category of scientific work) on the dissertation ["Title"] - considered within an expanded thematic scenario about secularization, its meanings and its consequences in the modern western world. Keywords: Modernity; secularization; faith; Charles Taylor; Religious Studies.
\end{abstract}




\section{RESUMEN}

Segun los datos quantitativos mensurados por Maurílio Ribeiro da Silva, en su religiografía (estado del arte) de la investigación sobre la secularización en los programas de pos-grado em Ciencias de la Religión en Brasil, se puede observar que el tema (secularización) presenta creciente importancia para los estudios de religión en Brasil; Además, se nota que el autor Charles Taylor - mismo considerando la importancia de su obra maestra, el libro La era secular - puede ser considerado aún poco discutido en las thesis y disertaciones defendidas en el area de la Ciencia de la Religión en nuestro país. Así, este texto, original en su concepción y redacción, y basado en la perspectiva metodologica bibliográfica y exploratória, es sobre la disertación [“Título"] - inserida en un escenário temático ampliado sobre la secularización, sus sentidos y sus decorrencias en el mundo moderno occidental.

Palavras clave: Modernidad; secularización; fe; Charles Taylor; Ciencia de la Religión.

\section{Introdução}

Na condição de objeto de estudo de várias áreas - Teologia, Filosofia, Ciências Humanas (em geral) e da Religião (em particular) -, a secularização parece ser inesgotável, pois nenhuma forma de discurso ou teoria é capaz de abarcar a totalidade do fenômeno que ela representa, com suas múltiplas consequências nas sociedades modernas.

Não por acaso, para ficarmos num só exemplo, Antônio Flávio Pierucci, a partir do final dos anos 1990, passou a defender "a contemporânea serventia de voltarmos a acessar aquele velho sentido", que é justamente o da "secularização em Max Weber". ${ }^{1}$ Acrescentamos: não somente em Max Weber ou na importante linhagem teórico-metodológica que ele formou, também é contemporânea a serventia de acessarmos os sentidos da categoria secularização em sua polissemia.

Se levada às últimas consequências, a chamada teoria da secularização - e longe de nós afirmarmos que a leitura de Weber leva necessariamente a esta conclusão - significa "morte de Deus", fim da religião ou de toda crença e experiência religiosa na história (pelo menos, do Ocidente). Segundo tal acepção, em muitos lugares do mundo, mas não em todo o mundo, a secularização reservou à religião o lugar do fanatismo.

Em contrapartida, em muitos lugares do mundo, mas não em todo o mundo, a religião está mais ativa e presente do que nunca. O que não consideramos - como o faz, por exemplo, Gilles Kepel (1991) - como uma espécie de "revanche do sagrado" na sociedade secular, pois não se trata de um jogo em "melhor de três": uma vitória para o "século" (morte de Deus), uma vitória para o "sagrado" (revanche de Deus) e, agora, em curso, a batalha final.

\footnotetext{
"Secularização em [ou: segundo] Max Weber: da contemporânea serventia de voltarmos a acessar aquele [ou: um] velho sentido", primeiramente, foi um trabalho apresentado por Pierucci no "Seminário Internacional Max Weber" (na UnB) em 1997. Depois, o texto foi publicado duas vezes: como artigo (PIERUCCI, 1998) e como capítulo de livro (PIERUCCI, 2000).
} 
Quanto ao caso, parecem-nos ajuizadas algumas considerações do assim chamado "último Berger" (2017, p. 9) em "Os múltiplos altares da modernidade": "A teoria da secularização, baseada na ideia de que a modernidade acarreta necessariamente um declínio da religião, serviu durante algum tempo como um paradigma para o estudo da religião". Porém, em face da evidência empírica, a teoria da secularização não se sustenta mais, pelo menos, não em único sentido, sendo necessário um novo paradigma (a teoria do pluralismo), que consiga lidar, ao mesmo tempo, com dois pluralismos: "a coexistência de diferentes religiões e a coexistência de discursos religiosos e seculares" (BERGER, 2017, p. 9).

Diante dos desafios de compreensão da secularização na modernidade ocidental, trata-se este texto, fundamentado em perspectiva metodológica bibliográfica e exploratória, de uma "análise de resultado de pesquisa": ${ }^{2}$ a dissertação, inserida num cenário temático ampliado, representado pelas pesquisas de Maurílio Ribeiro da Silva (2016; 2020) acerca da secularização.

\section{Uma religiografia (tomada de empréstimo) sobre a secularização em Ciências da Religião no Brasil}

A revista "Interações" (editada pelo PPG em Ciências da Religião da PUC Minas) publicou, em 2020 (v. 15, n. 2), em seção específica ("Debates e comunicações"), uma instigante contribuição intitulada "Religiografia das pesquisas sobre a secularização nas teses e dissertações dos Programas de Pós-Graduação em Ciências da Religião no Brasil”. O autor, Maurílio Ribeiro da Silva, já havia defendido sua dissertação, em 2016, no PPG em Ciências da Religião da PUC Minas (Área de concentração: "Religião e contemporaneidade"), intitulada "Secularização à brasileira: uma investigação sobre o estado da arte da discussão sobre a secularização a partir das teses e dissertações dos programas de pós-graduação em Ciências da Religião no Brasil de 1978 a 2012". ${ }^{3}$

De partida, uma pergunta: por que o recorte temporal da dissertação do autor vai de 1978 a 2012?

Em 1978, foi criado na Pontifícia Universidade Católica de São Paulo, o primeiro Programa de Pós-graduação stricto sensu em Ciências da Religião do Brasil, surgindo até o ano de 2012, outros nove programas. A primeira pesquisa sobre o tema da seculari-

\footnotetext{
De acordo com as "Diretrizes para autores e autoras" da revista Caminhando. Disponível em: https://www.metodista.br/revistas/revistas-metodista/index.php/Caminhando/about/ submissions\#authorGuidelines. Acesso em: 23 dez 2020.

3 Pesquisa que é o fundamento dos dados da comunicação publicada no periódico da PUC Minas.
} 
zação surge a partir do final da década de 90, e estende-se até o ano de 2003, quando ocorre um intervalo na produção, até a retomada da pesquisa em 2008. Daí em diante, verificou-se uma regularidade de produção de pesquisas até o ano de 2012, período delimitado nessa pesquisa. (SILVA, 2016, p. 16). ${ }^{4}$

$\mathrm{Na}$ sequência, importa-nos reconhecer o lugar simbólico - representado pela área de concentração - da dissertação de Silva e, por extensão, de seu texto em "Interações". Com isso, afirmamos a importância do debate quanto à secularização em toda tentativa acadêmica de tratar da religião na contemporaneidade. Segundo Eduardo Mendieta e Jonathan VanAntwerpen (2011, p. 11), em época anterior à nossa, foram levantadas questões acerca das relações entre o público e o privado, hoje (referem-se eles ao final da primeira década do século XXI), "são as categorias próprias do religioso e do secular - e do secularismo e da religião - as que se reexaminam, reelaboram e repensam". ${ }^{5}$

Tanto na dissertação (ao oferecer um estado da arte da discussão) como na comunicação (com uma religiografia das pesquisas), Silva (2016; 2020) contribui para um balanço quantitativo - mas não só - da presença do tema da secularização em dissertações e teses defendidas nos programas de Ciências da Religião no Brasil. A hipótese do autor a respeito de uma secularização à brasileira nos interessa menos do que os dados obtidos pelas pesquisas e transformados em quadros, gráficos, tabelas.

Além disso, situado cronologicamente entre a dissertação (2016) e a comunicação (2020), encontramos outro texto de Silva (2017, p. 371), intitulado "Bases epistemológicas das Ciências da Religião no Brasil: Estudo religiográfico da pesquisa docente nos Programas de Pós-Graduação em Ciências da Religião no Brasil", que oferece a seguinte informação:

O termo religiografia é novo no contexto das Ciências da Religião, e pode ser considerado basicamente como um tipo de investigação concentrado na sistematização e análise da produção realizada por autores no campo dos estudos da religião. Constitui um trabalho de levantamento do estado da arte sobre a literatura disponível sob determinado tema em determinado período. Cabe ao estudo religiográfico, a avaliação crítica

\footnotetext{
Em nota, Silva (2016, p. 16) informa que, "após esse período [ano de 2012], mais dois programas foram criados, totalizando, até o fechamento dessa pesquisa, doze Programas". Não pretendemos fazer uma atualização dos dados levantados por Silva, mas, sim, informar às pessoas interessadas que a temática da secularização acaba de ganhar mais uma discussão nos programas de nossa área.

5 A opinião de Mendieta e VanAntwerpen (2011) é válida por si, mas, também, por aquilo que aponta, pois são eles os editores do livro The Powver of Religion in the Public Sphere (utilizado por nós, neste artigo, em sua edição espanhola), resultante da aula magna em The Cooper Union (Nova Iorque), em 22 de outubro 2009, no formato de um diálogo público entre Jürgen Habermas, Charles Taylor, Judith Butler e Cornel West. Segundo o escopo desta análise, interessa-nos, particularmente, a presença de Taylor no debate.
} 
das pesquisas realizadas sobre a religião. Como ferramenta metodológica, a religiografia deve coletar, analisar, refletir, sistematizar, criticar e catalogar o conhecimento produzido sobre o fenômeno religioso. ${ }^{6}$

Por conseguinte, a considerar a comunicação de Silva publicada pela revista, associada com os critérios de inclusão adotados por ele desde a dissertação, ${ }^{7}$ alguns dados quantitativos que impõem uma interpretação qualitativa informam que, de 1999 a 2012, foram duas teses e sete dissertações sobre secularização defendidas nos PPGs em Ciências da Religião, sendo cinco delas em universidades do estado de São Paulo - UMESP (quatro) e Mackenzie (uma) - e quatro em Minas Gerais - UFJF (duas) e PUC Minas (duas). Pelos argumentos e temporalidades propostos por Silva (2016), há um suposto silêncio quanto ao tema da secularização nas teses e dissertações em ciências da religião de 1978 a 1999 - quer dizer, pelo menos, de acordo com a forma adotada por ele para mapear o estado da arte, ou seja, pela presença do descritor "secularização" nas palavras-chave de cada produto.

Os autores mais citados por número de pesquisas são (vamos listar somente os quatro primeiros, dentre os 10 levantados por Silva) Peter Berger (sete pesquisas), Friedrich Nietzsche (sete), Rubem Alves (seis) e Max Weber (seis). Aparecendo em apenas duas obras, Gianni Vattimo, por sua vez, é o autor mais vez citado (43); e Jürgen Habermas, que também é referido somente em dois trabalhos, é o segundo mais citado em número de vezes (37); Peter Berger aparece citado 16 vezes (ocupando a terceira posição, depois de Nietzsche). Em contrapartida, no quesito "obras mais citadas nas referências", com o livro "O dossel sagrado", Peter Berger ocupa o primeiro lugar (seis vezes) - e também o terceiro, com "Um rumor de anjos" (três vezes). ${ }^{8}$

6 Apresentado por Silva (2017) em congresso científico, trata-se, como ele mesmo informa, de um Projeto de Tese, financiado pela CAPES, sob orientação do prof. dr. Flávio Augusto Senra Ribeiro (que já havia orientado Silva no mestrado). O olhar atento ao currículo de Flávio Senra na Plataforma Lattes (disponível em: http://lattes.cnpq.br/0200938969199993) revela que, desde 2016 (pelo menos), ele se vale da categoria "religiografia" em projetos e orientações de pesquisa, bem como em publicações. Reconhecemos a importância da categoria para os estudos na área das Ciências da Religião, mas nossa genealogia para por aqui.

"A proposta inicial previa o estabelecimento das principais tendências teóricas, e das relações de produção em relação ao tempo, espaço geográfico, principais autores utilizados nas referências e principais instituições produtoras de pesquisas. Entretanto, com o desenvolvimento da pesquisa, foram inseridas as categorias das relações de produção em relação aos autores mais citados por obras, às obras mais utilizadas nas referências, as relações por tipo de instituição e pela confessionalidade das instituições" (SILVA, 2016, p. 17).

8 As informações acima podem ser consultadas no "APÊNDICE B - Estatísticas" da dissertação de Silva (2016, p. 145-151) ou na comunicação como um todo (SILVA, 2020). 
Dada a condição de destaque do sociólogo (que era também teólogo) Peter Berger dentro da história do conceito secularização, o primeiro resultado obtido por Silva (p. 463, 2020) em sua religiografia das pesquisas não pode ficar sem um comentário denso, ainda que breve: "a temática foi analisada nas pesquisas sob a ótica dualista de oposição entre secularização e religião. Essa constatação se dá em oito, dos nove trabalhos analisados, o que demonstra a influência de Peter Berger (influenciado por Max Weber) na conceituação da secularização".

Além disso, ao relacionar o tempo tardio da primeira publicação sobre secularização nos PPGs de Ciências da Religião no Brasil, após cerca de duas décadas da emergência e institucionalização da área no país, Silva (p. 463-464, 2020) afirma que foi na mesma época que Peter Berger "voltou atrás em suas considerações sobre a secularização, além do fato de que temas como dessecularização, retorno do sagrado e reencantamento do mundo já estavam em pauta". Aqui, não temos como estender o debate a respeito das relações possíveis entre um primeiro e um segundo Peter Berger no que concerne a seu posicionamento acerca da secularização, mas a mera presença dos dois livros de sua autoria nas teses e dissertações brasileiras - "O dossel sagrado" (original de 1967) e "Um rumor de anjos" (original de 1969) -, segundo o estado da arte (religiografia) proposto por Silva, revela que a crise do conceito "secularização" no pensamento de Berger é mais processual e constante (desde os anos 1970, pelo menos) do que episódica, isto é, a partir do final do século XX.

\section{Uma contribuição para a religiografia sobre a secularização em Ciências da Religião no Brasil}

Segundo os dados da pesquisa de Silva (2016; 2020), Charles Taylor não é citado nenhuma vez nas dissertações e teses na área de Ciências da Religião no Brasil dentro do recorte temporal proposto - o que é de causar surpresa, pois a obra-prima do autor, The Secular Age, é de 2007, com tradução para o português, em edição brasileira, de 2010..$^{9}$ Assim, na comunicação publicada por Silva (2020) em "Interações", Taylor nem aparece; na dissertação, por iniciativa do autor - e não das obras analisadas, reiteramos -, o nome do filósofo canadense é mencionado nove vezes, mas a questão de conteúdo está resumida a uma só discussão, na seção "2.1 A questão da seculariza-

\footnotetext{
Para radicalizar o argumento, não será demasiado lembrar que o livro A Secular Age (Partes I a III) "é fruto das minhas [de Taylor] Gifford Lectures, em Edimburgo, proferidas na primavera de 1999 e denominadas Living in a Secular Age? [Vivendo numa Era Secular?]” (TAYLOR, 2010, p. 7).
} 
ção" (SILVA, 2016, p. 24-33). Nela, Taylor compõe uma lista com outros sociólogos e filósofos (não brasileiros) que tratam da relação entre religião e secularização em suas obras - só para esclarecer, teólogos foram também discutidos dentro da mesma seção, mas em separado. Depois de haver iniciado o debate sociológico com Peter Berger, "em virtude de ter sido o autor mais citado nas referências e dissertações analisadas" (SILVA, 2016, p. 29), o autor aponta a relevância de Taylor: "Outro importante teórico da secularização é o filósofo Charles Taylor” (SILVA, 2016, p. 30).

Na sequência, Silva se vale de uma discussão de secularização em Taylor, que ele busca, na verdade, no artigo "Charles Taylor e a secularização como novas condições de crença” de Eurides Rodrigues - e que vai ser citada por nós, aqui, nas palavras do próprio Rodrigues (p. 190-191, 2015):

[...] o termo secularização é uma ideia ou teoria com sentidos múltiplos, um conceito polissêmico. Ela tanto pode servir como teoria explicativa de algo que teria ocorrido na civilização Ocidental, quanto pode ter a própria existência contestada por muitos estudiosos.

Ainda de acordo com Taylor, as teorias da secularização giram em torno a dois eixos explicativos. O primeiro entende por secularização a "retração da religião na vida pública” (495) [página citada do livro "Uma era secular”]. O segundo por "declínio em termos de fé e prática”. Taylor, por sua vez, a entende como um conjunto de profundas transformações ocorridas nas sociedades Ocidentais que trouxe consigo, dentre outras coisas, uma mudança nas condições da fé ou novas condições para a experiência da fé.

Para Taylor, "a crença em Deus não acabou”, conclui Silva (2016, p. 31). E, para legitimar seus argumentos, Silva faz uso de uma citação do filósofo canadense - que nós vamos buscar diretamente em Taylor (2010, p. 513):

[...] certamente tem havido um "declínio" da religião. A fé religiosa passou a existir num campo de escolhas que inclui várias formas de objeção e rejeição; a fé cristã existe em um campo em que há também um amplo leque de outras opções espirituais. Porém, a história que nos interessa não é simplesmente uma história de declínio, mas também de uma nova determinação do lugar do sagrado ou espiritual na vida individual e social. Essa nova localização tornou-se uma oportunidade para composições da vida espiritual em novas formas, e para novos modos de existência tanto na relação com Deus quanto fora dela. ${ }^{10}$

Daí a importância do texto de Taylor (2011) - "Por que necessitamos de uma redefinição radical do secularismo" - no já mencionado livro organizado

10 Na dissertação de Silva (2016), Taylor volta a aparecer somente na conclusão, para retomada em forma de síntese do que foi exposto acima (claro, dentro da temática de sua pesquisa, que é a "secularização à brasileira"), e, por óbvio, nas referências. 
por Mendieta e VanAntwerpen, ou seja, porque não há justificativa para considerarmos a religião como um caso apartado dentre outras visões de mundo não religiosas, como se somente a razão não religiosa fosse capaz de garantir fundamentos epistêmicos confiáveis, bem como a ética e a política corretas para o bem viver. Para quem discute a secularização no campo das Ciências da Religião, a opinião de Taylor tem de ser considerada - mesmo que para não concordar com ela. Ele enxerga na "era moderna" uma obsessão contra a religião que não faz muito sentido, por se tratar de um reducionismo resultante (do mito) do Iluminismo, bem como das consequências da Revolução Francesa e da constituição (em mais de um sentido) dos EUA.

O que mantém o equívoco na forma de o mundo atual pensar na secularização, para Taylor (2011), é que tudo parece se resumir à relação (ou separação) entre Estado e Igreja; mas a questão que se impõe é outra - e está relacionada ao papel do Estado (o que ele deve fazer) em face da diversidade. E Taylor (2011, p. 56) vai além para explicar os fundamentos dessa confusão na contemporaneidade:

Creio que sua origem esteja no que se poderia chamar de o mito da Ilustração. Existe uma opinião comum que vê a Ilustração (Aufklärung, Lumières) como o passo da obscuridade à luz, ou seja, um passo absoluto e sem restrição de um mundo cheio de erros e ilusões para outro, no qual a verdade está, finalmente, à nossa disposição. A isto se deveria acrescentar imediatamente que a opinião contrária caracteriza o pensamento "reacionário": a Ilustração seria um erro sem paliativos, um esquecimento massivo de verdades saudáveis e necessárias sobre a condição humana.

Cabe retomar (para esclarecer) o porquê de direcionarmos a atenção para Charles Taylor nesta análise de pesquisa em forma de artigo. Antes de tudo, para contribuir com um dado para a atualização do estado da arte e da religiografia de Silva (2016; 2020). Não que tenhamos acompanhado o descritor "secularização" nas dissertações e teses dos PPGs em Ciências da Religião no Brasil de 2012 até hoje - como já deixamos claro. Mas, antes, porque este nosso trabalho resulta de uma dissertação sobre a temática da secularização no pensamento de Taylor, notadamente no livro "Uma era secular", que se divide em cinco grandes partes, nas quais, segundo nosso entendimento, Taylor procura responder a duas perguntas fundamentais. A primeira diz respeito ao que significa considerar que vivemos numa era secular; e a segunda se relaciona ao por que passamos de uma sociedade (no Ocidente), na qual era praticamente impossível não acreditar em Deus, para outra, na qual a fé representa uma dentre tantas opções. Para responder às questões (ou temáticas) propostas, o autor apresenta três formas de com- 
preender a secularização, ou seja, três sentidos da secularização. O primeiro é o da tradicional separação entre Igreja e Estado; o segundo afirma que a secularização consiste no abandono de convicções e práticas religiosas; o terceiro (e último), ao qual Taylor se dedica com boa dose de novidade, é a compreensão da fé como uma opção dentre tantas outras.

Nas palavras do próprio Taylor (2010, p. 41), apresenta-se a pergunta-chave quando o assunto é a secularização: “[...]: por que era praticamente impossível não acreditar em Deus, digamos, no ano de 1500, em nossa sociedade ocidental, ao passo que, em 2000, muitos de nós acham isso não apenas fácil, mas até mesmo inescapável?". Segundo ele, as características do mundo na primeira época mencionada (por volta do ano 1500) proporcionavam a crença, pois a presença de Deus na natureza e na sociedade era inegável:

\begin{abstract}
Sem dúvida, parte da resposta é que, naqueles dias, todos acreditavam e, assim, as alternativas pareciam extravagantes. Mas isto apenas empurra a questão ainda mais para trás. Precisamos compreender a forma como as coisas se modificaram. Como as alternativas tornaram-se concebíveis?

Uma importante parte do panorama é que inúmeras características do mundo deles pronunciavam-se a favor da crença, tornando a presença de Deus aparentemente inegável (TAYLOR, 2010, 41).
\end{abstract}

São mencionadas, então, três das características que justificavam a presença inegável de Deus na história. A primeira retoma a noção de que o mundo em que viviam nossos antepassados, segundo seu próprio entendimento, possuía um lugar no cosmos (e Deus o mantinha ordenado por meio de seus atos). Deus estava também na base da fundação e sustentação da pólis (reino, igreja etc.) - eis a segunda característica. A terceira: "As pessoas viviam em um mundo 'encantado'. Esta talvez não seja a melhor expressão; ela parece evocar lampejos e fadas. Mas estou evocando aqui a sua negação, a expressão de Weber 'desencantamento"' (TAYLOR. 2010, p. 42). ${ }^{11}$ Aqui, tocamos num ponto que merece ser destacado, embora não possa ser desenvolvido, por fugir ao escopo deste texto: importa também voltarmos a acessar aquele velho sentido de "desencantamento do mundo" em Weber - e também nos seus críticos que defendem uma espécie de reencantamento do mundo (pela religião) -, que está na base de toda a discussão em tela.

Prossegue Taylor em seus arrazoados, a história da modernidade não deve ser contada tão somente por perdas e subtrações, abandono e desaparecimento - fim da religião. Por não aceitar, digamos, a sociologia oficial ou

11 "O ateísmo chega perto de ser inconcebível em um mundo com essas três características" (TAYLOR, 2010, p. 42). 
hegemônica quanto à teoria da secularização, Taylor decidiu oferecer uma interpretação original para o fenômeno em sua empiria, e foi assim que escreveu "Uma era secular". Isto é, ele nos leva a pensar em múltiplas modernidades, pois, dentre outras razões, não há como analisar globalmente um fenômeno que se manifesta localmente de variegadas formas. Além disso, está a propor que a fé em Deus (tomado, aqui, como aquele que é transcendente, que se revela, ou seja, o Deus da teologia) não é mais axiomática nem obrigatória, restam alternativas que não sejam, de um lado, "a morte de Deus" e, de outro, "a revanche de Deus".

A proposta de Taylor, original a ponto de destoar do restante do corpus teórico já produzido sobre a temática, é que a secularização pode ser considerada tanto no sentido primeiro (separação entre Estado e Igreja) como no segundo (abandono da fé, e de convicções e práticas religiosas), mas, hoje (na era moderna ou secular), ela se desvela mesmo é no terceiro sentido: a fé como uma opção dentre tantas outras - "e, em geral, não a mais fácil de ser abraçada" (TAYLOR, 2010, p. 15).

Problematizar (ou relativizar) o conceito de secularização não significa desistir dele - nem como evidência empírica nem como construto teórico. Para Taylor, trata-se, na verdade, de buscar alternativas na forma de compreensão do conceito (e, portanto, da própria sociedade) dentro da dinâmica histórica. Ao perceber que o óbvio no desenrolar da história, segundo sua visão de mundo, estava a desmantelar a teoria clássica da secularização (na linhagem weberiana), Taylor assumiu a necessidade de um novo entendimento, ou seja, demonstrar que a secularização não traz consigo, necessariamente, o fim da religião, mas, sim, novas formas possíveis de se viver a fé - mas não como uma opção-padrão, ou seja, espécie de única escolha resultante de uma falta de alternativas outras.

\section{Considerações finais}

Nada nos impede a compreensão de que o primeiro sentido da secularização (separação entre Igreja e Estado) proposto por Taylor possa conviver com o terceiro (a fé e a crença religiosa como opções) - deixando o segundo sentido (fim da religião) para sociedades ou grupos muito particulares em que a religião realmente deixou de existir ou passou a ser sinônimo de fanatismo. A dissertação que estamos analisando dedica seu último capítulo a discutir o caso brasileiro como o de um Estado separado da Igreja (religião oficial) desde a primeira Constituição republicana de 1891, mas que não impede o pluralismo de expressões religiosas em seu território e no meio de suas 
gentes. Podemos acrescentar: com exceção de algumas expressões nítidas de preconceito contra religiões e religiosos - de fora do campo das religiões, bem entendido, pois também há discriminação entre as religiões -, a razão religiosa não se encontra proibida de expressão no jogo de forças com as razões não religiosas na esfera pública.

Não temos espaço neste texto para trabalhar algo que restou da banca de defesa da dissertação, isto é, a pergunta (ou o anseio) por um discurso "desde o sul" - ou, de modo ainda mais particular, "do Brasil" - que faça uma crítica epistemológica das teorias da secularização produzidas pela intelectualidade nos países do Norte ocidental. Ainda assim, registramos que a dica para um possível caminho já foi dada pelo próprio Silva (2016; 2020), ao retratar em suas pesquisas que o único autor brasileiro mencionado nas teses e dissertações a tratar da secularização no Brasil é Rubem Alves, citado em seis das pesquisas elencadas pelo autor (ao lado de Max Weber, não é pouca coisa, dentre os autores mais citados). Mas é de causar algum incômodo o fato de que a única obra de Rubem Alves, nas seis pesquisas mencionadas, tenha sido o livro (bastante introdutório) "O que é religião", no qual "ele conceitua a religião como uma construção simbólica criada a partir do desejo, da busca de sentido humano" (SILVA, 2016, p. 41-42).

Ora, é de conhecimento amplo nos estudos de religião no Brasil que, já em 1978, Rubem Alves havia feito aquele que pode ser considerado o primeiro balanço das publicações de Sociologia (por extensão, Ciências Sociais) da Religião no Brasil. O ano da publicação é de fundamental importância, pois coincide com o início da história formal das Ciências da Religião no Brasil, algo que foi tão bem trabalhado por Silva (2016; 2020). Em seu artigo, cujo título (“A volta do sagrado") já anuncia a discussão e a polêmica, Rubem Alves (p. 123-125, 1978) reserva uma seção inteira para "a temática da secularização e as religiões de ajustamento". Eis um bom começo para uma futura pesquisa sobre a religiografia de autores brasileiros em pesquisas sobre a secularização no Brasil.

\section{Referências bibliográficas}

ALVES, Rubem A. A volta do sagrado: os caminhos da Sociologia da Religião no Brasil. Religião e Sociedade, Rio de Janeiro, n. 3, p. 109-141, 1978.

BERGER, Peter L. Os múltiplos altares da modernidade: rumo a um paradigma numa época pluralista. Petrópolis: Vozes, 2017.

KEPEL, Gilles. A revanche de Deus: cristãos, judeus e muçulmanos na reconquista do mundo. São Paulo: Siciliano, 1991.

MENDIETA, Eduardo; VANANTWERPEN, Jonathan. Introducción. In: MENDIETA, 
Eduardo; VANANTWERPEN, Jonathan (Eds.). El poder de la religión en la esfera pública. Madrid: Trotta, 2011, p. 11-22.

PIERUCCI, Antônio Flávio. Secularização em Max Weber: da contemporânea serventia de voltarmos a acessar aquele velho sentido. Revista Brasileira de Ciências Sociais, v. 13, n. 37, p. 43-72, 1998.

PIERUCCI, Antônio Flávio. Secularização segundo Max Weber: da contemporânea serventia de voltarmos a acessar aquele velho sentido. In: SOUZA, Jessé (Org.). A atualidade de Max Weber. Brasília, DF: Editora da Universidade de Brasília, 2000, p. 105-162.

RODRIGUES, Eurides. Charles Taylor e a secularização como novas condições de crença. Religare, v. 12, n. 1, p. 172-195, 2015. Disponível em: file:///C:/Users/usuario/ Downloads/27257-Texto\%20do\%20artigo-58296-1-10-20151231\%20(2).pdf. Acesso em: 15 dez. 2020.

SILVA, Maurílio Ribeiro da. Bases epistemológicas das Ciências da Religião no Brasil: Estudo religiográfico da pesquisa docente nos Programas de Pós-Graduação em Ciências da Religião no Brasil. II Congresso Interdisciplinar de Pesquisa, Iniciação Científica e Extensão do Centro Universitário Metodista Izabela Hendrix, 2017, Belo Horizonte/ MG. Anais. Belo Horizonte: Centro Universitário Metodista Izabela Hendrix, 2017. Disponível em: file:///C:/Users/usuario/Downloads/P+\%C3\%ADginas $\% 20 \mathrm{de} \% 20$ Anais.2017.p.369-376\%20(1).pdf. Acesso em: 23 dez. 2020.

SILVA, Maurílio Ribeiro da. Religiografia das pesquisas sobre a secularização nas teses e dissertações dos programas de pós-graduação em Ciências da Religião no Brasil. Interações, v. 15, n. 2, p. 461-469, 2020. Disponível em: http://periodicos.pucminas.br/index.php/interacoes/article/view/24582/17345. Acesso em: 30 nov. 2020.

SILVA, Maurílio Ribeiro da. Secularização à brasileira: uma investigação sobre o estado da arte da discussão sobre a secularização a partir das teses e dissertações dos programas de pós-graduação em Ciências da Religião no Brasil de 1978 a 2012. 2016. 151 f. Dissertação (Mestrado em Ciências da Religião) - PPG em Ciências da Religião, PUC Minas, Belo Horizonte-MG, 2016. Disponível em: file:///C:/Users/usuario/Downloads/PONTIFICIA UNIVERSIDADE_CATOLICA DE_MINA\%20(1).pdf.Acesso em: 30 nov. 2020.

TAYLOR, Charles. Por qué necessitamos de uma redefinição radical do secularismo. In: MENDIETA, Eduardo; VANANTWERPEN, Jonathan (Eds.). El poder de la religión en la esfera pública. Madrid: Trotta, 2011, p. 39-60.

TAYLOR, Charles. Uma era secular. São Leopoldo: Editora da UNISINOS, 2010. 